\title{
Middle East Respiratory Syndrome coronavirus (MERS- $\mathrm{CoV}$ ) serology in major livestock species in an affected region in Jordan, June to September 2013
}

C B Reusken (chantal.reusken@rivm.nl) ${ }^{1,2,3}$, M Ababneh ${ }^{1,4}$, V S Raj ${ }^{1,3}$, B Meyer $^{5}$, A Eljarah ${ }^{6}$, S Abutarbush ${ }^{6}$, G J Godeke ${ }^{2}$, T M

Bestebroer ${ }^{3}$, I Zutt ${ }^{2}$, M A Müller ${ }^{5}$, B J Bosch7, P J Rottier7, A D Osterhaus ${ }^{3}$, C Drosten ${ }^{5}$, B L Haagmans ${ }^{3}$, M P Koopmans ${ }^{2,3}$

1. These authors contributed equally to this work

2. Centre for Infectious Disease Control, Division Virology, National Institute for Public Health and the Environment, Bilthoven, the Netherlands

3. Department of Viroscience, Erasmus Medical Centre, Rotterdam, the Netherlands

4. Department of Veterinary Basic Medical Sciences, Faculty of Veterinary Medicine, Jordan University of Science and Technology, Irbid, Jordan

5. Institute of Virology, University of Bonn Medical Centre, Bonn, Germany

6. Department of Veterinary Clinical Sciences, Faculty of Veterinary Medicine, Jordan University of Science and Technology, Irbid, Jordan

7. Department of Infectious Diseases and Immunology, Virology Division, Utrecht University, Faculty of Veterinary Medicine, Utrecht, the Netherlands

Reusken CB, Ababneh M, Raj VS, Meyer B, Eljarah A, Abutarbush S, Godeke GJ, Bestebroer TM, Zutt I, Müller MA, Bosch BJ, Rottier PJ, Osterhaus AD, Drosten C, Haagmans BL, Koopmans MP. Middle East Respiratory Syndrome coronavirus (MERS-CoV) serology in major livestock species in an affected region in Jordan, June to September 2013. Euro Surveill. 2013;18(50):pii=20662. Available online: http://www.eurosurveillance.org/ViewArticle.aspx?Articleld=20662

Article submitted on 04 December 2013 / published on 12 December 2013

Between June and September 2013, sera from 11 dromedary camels, 150 goats, 126 sheep and 91 cows were collected in Jordan, where the first human MiddleEast respiratory syndrome (MERS) cluster appeared in 2012. All sera were tested for MERS-coronavirus (MERS-CoV) specific antibodies by protein microarray with confirmation by virus neutralisation. Neutralising antibodies were found in all camel sera while sera from goats and cattle tested negative. Although six sheep sera reacted with MERS-CoV antigen, neutralising antibodies were not detected.

In the period between June and September 2013, sera from 11 dromedary camels, 150 goats, 126 sheep and 91 cows were collected predominantly in the al Zarqa governorate, Jordan, where the first human Middle-East respiratory syndrome (MERS) cluster appeared in April 2012 [1]. All sera were tested for the presence of MERScoronavirus (MERS-CoV) specific antibodies by protein microarray with confirmation by virus neutralisation. Neutralising antibodies to MERS-CoV were found in all sera from dromedary camels while the sera from goats and cattle tested negative. Although six of 126 sheep sera reacted with the MERS-CoV antigen, neutralising antibodies were not detected. The reactivity of sheep sera from this region observed in the microarray warrants further study.

\section{Background}

In 2012 MERS-CoV was identified in patients with severe respiratory disease in the Middle East. As of 2 December 2013, a total of 163 laboratory-confirmed cases including 70 deaths have been reported to the World Health Organization (WHO) [2]. All cases reported to date were linked to Jordan, Kuwait, Oman, Qatar, Saudi Arabia (SA) or the United Arab Emirates (UAE). Human to human transmission has been observed in healthcare and family settings [3]. Various studies indicate that the observed MERS-CoV diversity in humans results from multiple independent introductions in the human population in the Middle East [5-7] and the number of these sporadic, primary infections is still increasing [2]. The animal reservoir(s) for MERS$\mathrm{CoV}$ are still unknown but serological studies demonstrated that dromedary camels in the Canary Islands, Egypt and Oman have been infected with MERS-CoV or MERS-related-CoV $[8,9]$. Of these countries, human cases have only been detected in Oman [2].

Data provided by the Food and Agriculture Organization of the United Nations (FAO) from 2012 show that cows, dromedary camels, goats and sheep are the main sources of meat and milk in the affected countries [4]. In addition, in Saudi Arabia, where the majority of MERS cases have been reported, roughly one sheep is sacrificed for each pilgrim or one camel for seven pilgrims in the Hajj (yearly Muslim pilgrimage to Mecca), which can amount up to the slaughter and worldwide distribution of meat of around three million MiddleEastern sheep and camels, based on the pilgrim numbers reported for 2011 and 2012 [10]. The continued occurrence of human MERS cases, the presence of neutralising antibodies in camels and the extensive animal exposure (including animal products) of humans warrant extensive studies in livestock aimed at identifying the possible reservoir of MERS-CoV. 


\section{FIGURE 1}

Animal sampling locations for the MERS-CoV serological study, relative to the location where MERS-CoV human cases were identified in April 2012, Jordan, June-September 2013

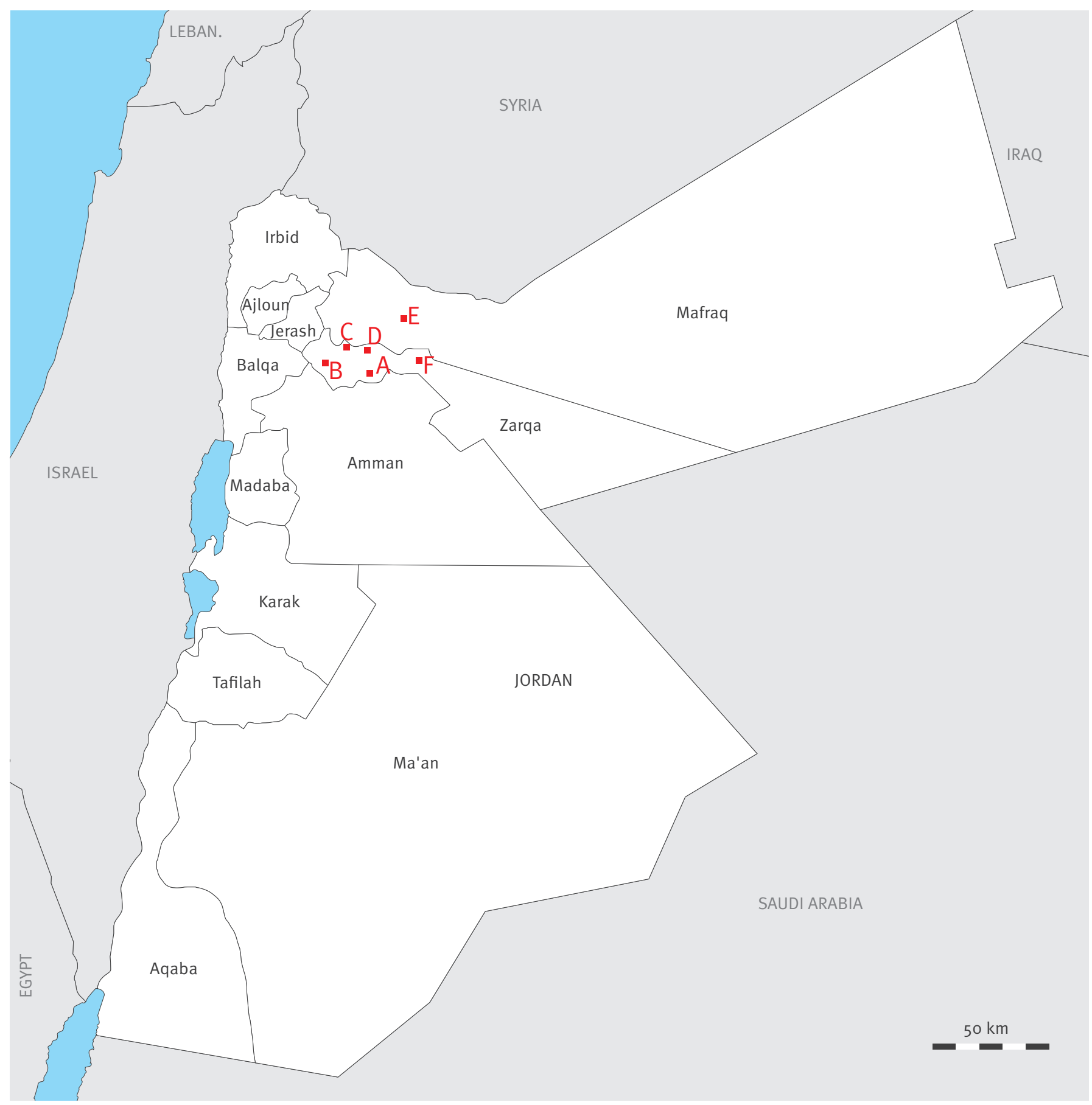

MERS-CoV: Middle East Respiratory Syndrome coronavirus.

A represents Al-Zarqa, the city were the first human Middle-East respiratory syndrome cases were identified in April 2012.

B-F are locations where animal sampling took place between June and September 2013.

Source: map adapted from: http://d-maps.com/carte.php?num_car=5402\&lang=en 
Characteristics of animals included in the Middle East Respiratory Syndrome (MERS) coronavirus serological study, Jordan, June-September 2013 ( $n=378$ animals)

\begin{tabular}{|c|c|c|c|c|}
\hline Animals (total numbers) & Location $^{\mathrm{a}, \mathrm{b}}$ & Number & Sex & Age \\
\hline Dromedary camels $(n=11)$ & $\mathrm{E}^{\mathrm{c}}$, outdoors & 11 & M & 3-14 months \\
\hline \multirow[t]{4}{*}{ Sheep of Awassi breed $(n=126)$} & $\mathrm{E}^{\mathrm{c}}$, indoors & 20 & $\mathrm{~F}$ & $>2$ years \\
\hline & C, outdoors & 53 & $F+M$ & All ages $^{d}$ \\
\hline & D, outdoors & 27 & $\mathrm{~F}+\mathrm{M}$ & $>2$ years \\
\hline & $\mathrm{B}$, indoors & 26 & $F+M$ & All ages $^{d}$ \\
\hline \multirow[t]{2}{*}{ Cows $(n=91)$} & C, indoors & 35 & $\mathrm{~F}$ & Unknown \\
\hline & $\mathrm{F}$, indoors & 56 & $\mathrm{~F}$ & Unknown \\
\hline \multirow[t]{3}{*}{ Goats of local breed $(n=150)$} & D, indoors & 10 & $\mathrm{~F}+\mathrm{M}$ & Unknown \\
\hline & C, unknown & 91 & $F+M$ & Unknown \\
\hline & B, unknown & 49 & $F+M$ & Unknown \\
\hline
\end{tabular}

M: male; F: female.

a The letters B, C, D, E, and F refer to locations indicated in Figure 1.

${ }^{b}$ If known, it is indicated whether the animals were kept indoors or outdoors.

c The respective locations of the sheep and camels were $5 \mathrm{~km}$ apart and there was no contact between the sheep and camels.

${ }^{d}$ Females were older than 2 years and males were younger than 6 months.

In April 2012, an outbreak of acute respiratory illness occurred in an intensive care unit in a public hospital in Zarqa city, Zarqa governorate, Jordan. Retrospective testing identified MERS-CoV as the confirmed and probable causative agent of two and 11 patients respectively. Ten people in the outbreak were healthcare workers (HCW). The two confirmed cases, a HCW and an admitted patient, died [1]. Although epidemiological investigations identified limited nosocomial transmission, the primary source for MERS-CoV transmission to humans was not identified.

\section{Middle East Respiratory Syndrome coronavirus serological study in livestock}

Between June and September 2013, sera as well as faecal swabs from 11 dromedary camels, 150 goats, 126 sheep and 91 cows were collected predominantly in the al Zarqa governorate, Jordan (Table 1, Figure 1). All sera were tested for the presence of IgG antibodies reactive with MERS-CoV, Severe Acute Respiratory Syndrome coronavirus (SARS-CoV), and human coronavirus OC43 (HCoV-OC43) $\mathrm{S}_{1}$ antigens exactly as described before $[9,11]$. HCoV-OC43 is serologically closely related to bovine coronavirus ( $\mathrm{BCoV}$ ) and used as a proxy to detect antibodies against $\mathrm{BCoVs}$ that are commonly circulating in ungulates [9].

All 11 dromedary camel sera and six of 126 sheep sera had antibodies against the MERS-CoV S1 antigen while there was no reactivity in goat and cow sera. Four of 11 dromedary camels, 23/91 cows, 128/150 goats and all sheep reacted with $\mathrm{HCOV}-\mathrm{OC}_{43}$ antigen. None of the sera bound to SARS-CoV antigen (Figure 2).
For confirmation, all camel and sheep sera $(n=137)$ were tested in a MERS-CoV neutralisation assay, exactly as described before [9]. All camel sera had MERS-CoV neutralising antibodies with titres varying between 1:20 and 1:80, while no neutralising antibodies were detected in the sheep sera (Table 2 and data not shown). As coronavirus serology is potentially complicated due to the general circulation of BCoVs in these four livestock species (cross-reactivity needs to be excluded), a comparative plaque reduction neutralisation test (PRNT) for MERS-CoV and BCoV was performed on all camels sera and a subset of goat, sheep and cow sera, exactly as described before [9] (Table 2). All camel sera inhibited MERS-CoV plaque formation with titres varying between 1:40 and 1:80, while again no inhibition was observed with the selection of sheep sera. Four of the 11 camel sera also inhibited $\mathrm{BCoV}$ plaque formation with titres between 1:160 and $1: 320$, confirming the microarray results for these samples. BCoV neutralising titres varied between 1:40 and $1: 160$ for the selection of sheep sera, between 1:40 and 1:320 for the subset of goat sera and between 1:40 and 1:>1,280 for the subset of bovine sera.

Faecal samples of camels and sheep were analysed for identification of viral sequences using pancoronavirus and specific polymerase chain reaction (PCR) methods [9]. Three BCoV sequences but no MERS-CoV or MERSrelated $\mathrm{CoV}$ sequences were obtained from sheep rectal swabs.

\section{Discussion}

Here, we describe a serological study in various livestock species $(n=378)$ of economic importance in a 


\section{FIGURE 2}

Reactivity of livestock sera $(n=378)$ from Jordan with three coronavirus S1 antigens

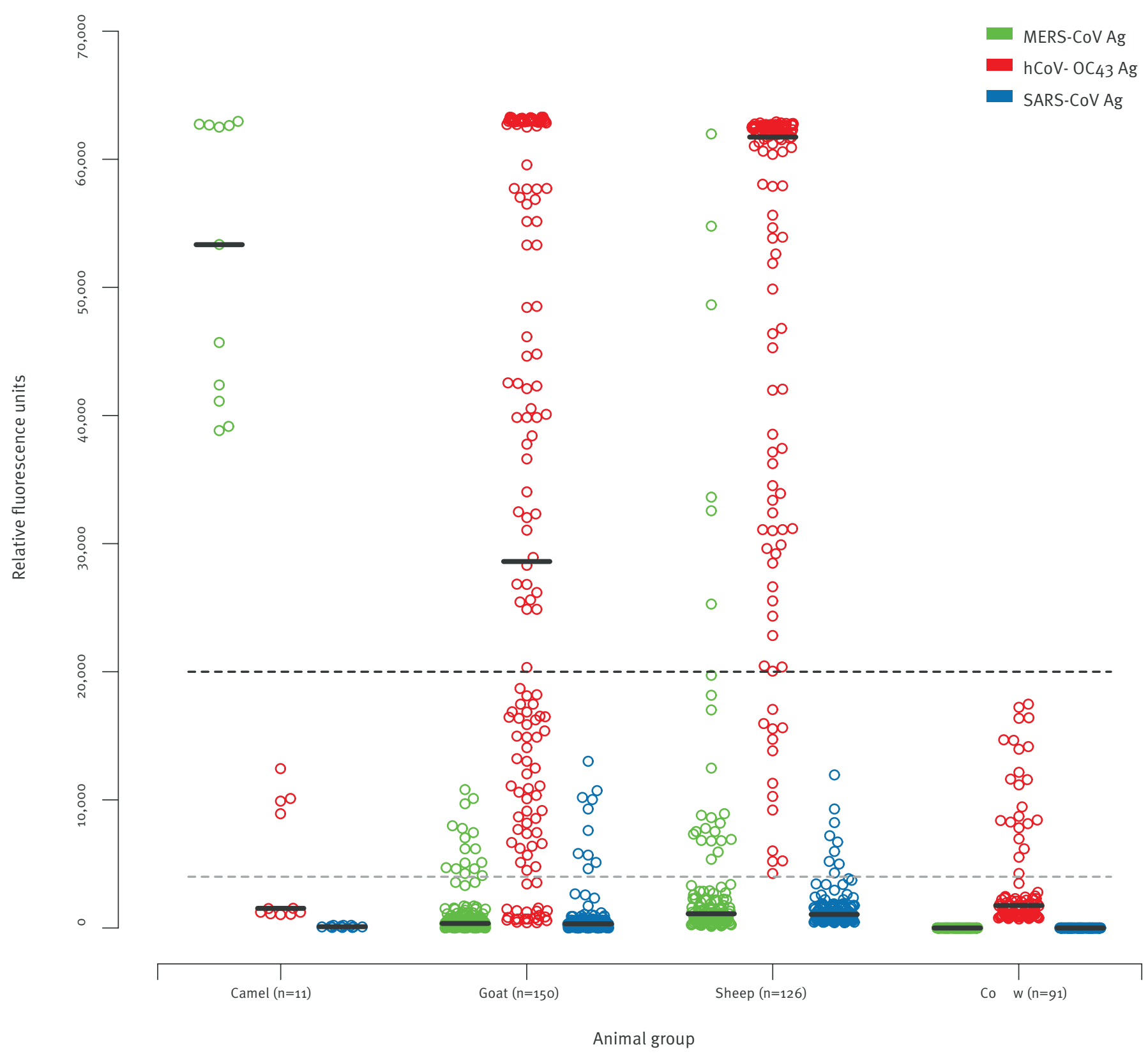

Ag: antigen; MERS-CoV: Middle East Respiratory Syndrome coronavirus; hCoV-OC43: human coronavirus OC43; SARS-CoV: Severe Acute Respiratory Syndrome coronavirus.

Column scatterplot of relative fluorescent intensities per antigen ( $y$-axis) measured by protein microarray for dromedary camel ( $n=11$ ), goat $(n=150)$, sheep $(n=126)$ and cow $(n=91)$ sera from Jordan at serum dilution 1:20.

Black lines indicate medians. Dashed black line is cutoff of the assay for MERS-CoV. Dashed grey line is cutoff of the assay for HCoV-OC 43. 


\section{TABLE 2}

Results of neutralising assays for Middle East Respiratory Syndrome coronavirus and bovine coronavirus, serological study in livestock, Jordan, June-September 2013

\begin{tabular}{|c|c|c|c|}
\hline & $\begin{array}{c}\text { Number of serum } \\
\text { samples }\end{array}$ & $\begin{array}{c}\text { Positive MERS-CoV neutralisation } \text { titre }^{a} \\
n \text { (titres) }\end{array}$ & $\begin{array}{c}\text { Positive } \mathrm{BCoV} \text { neutralisation } \text { titre }^{\mathrm{b}} \\
\mathrm{n} \text { (titres) }\end{array}$ \\
\hline \multicolumn{4}{|c|}{ Dromedary camels $n=11$} \\
\hline \multicolumn{4}{|c|}{ MERS-CoV antigen array signal (RFU) } \\
\hline$\langle 10,000$ & 0 & o (NS) & o (NS) \\
\hline $10,000-20,000$ & o & o (NS) & o (NS) \\
\hline $20,000-30,000$ & o & o (NS) & o (NS) \\
\hline $30,000-40,000$ & 2 & $2(1: 20$ to $1: 40)$ & o (NS) \\
\hline$>40,000$ & 9 & $9(1: 20$ to $1: 80)$ & $4(1: 160$ to $1: 320)$ \\
\hline \multicolumn{4}{|c|}{ hCoV-OC43 antigen array signal (RFU) } \\
\hline$\langle 10,000$ & 9 & $9(1: 20$ to $1: 80)$ & $2(1: 320)$ \\
\hline $10,000-20,000$ & 2 & $2(1: 80)$ & $2(1: 160)$ \\
\hline $20,000-30,000$ & o & o (NS) & o (NS) \\
\hline $30,000-40,000$ & 0 & o (NS) & o (NS) \\
\hline$>40,000$ & 0 & o (NS) & o (NS) \\
\hline \multicolumn{4}{|l|}{ Sheep $n=10$} \\
\hline \multicolumn{4}{|c|}{ MERS-CoV antigen array signal (RFU) } \\
\hline$\langle 10,000$ & 4 & o (NS) & $3(1: 80$ to $1: 160)$ \\
\hline $10,000-20,000$ & 0 & o (NS) & o (NS) \\
\hline $20,000-30,000$ & 1 & o (NS) & $1(1: 40)$ \\
\hline $30,000-40,000$ & 2 & o (NS) & $2(1: 40$ to $1: 160)$ \\
\hline 240,000 & 3 & o (NS) & $2(1: 40$ to $1: 80)$ \\
\hline \multicolumn{4}{|c|}{ hCoV-OC43 antigen array signal (RFU) } \\
\hline$\langle 10,000$ & 1 & o (NS) & o (NS) \\
\hline $10,000-20,000$ & 0 & o (NS) & o (NS) \\
\hline $20,000-30,000$ & 1 & o (NS) & o (NS) \\
\hline $30,000-40,000$ & 2 & o (NS) & $2(1: 40)$ \\
\hline$>40,000$ & 6 & o (NS) & $6(1: 40$ to $1: 160)$ \\
\hline \multicolumn{4}{|l|}{ Goat $n=8$} \\
\hline \multicolumn{4}{|c|}{ MERS-CoV antigen array signal (RFU) } \\
\hline$<10,000$ & 7 & o (NS) & $3(1: 40$ to $1: 320)$ \\
\hline $10,000-20,000$ & 1 & o (NS) & $1(1: 160)$ \\
\hline $20,000-30,000$ & o & o (NS) & o (NS) \\
\hline $30,000-40,000$ & o & o (NS) & o (NS) \\
\hline 240,000 & o & o (NS) & o (NS) \\
\hline \multicolumn{4}{|c|}{ hCoV-OC43 antigen array signal (RFU) } \\
\hline$\langle 10,000$ & 3 & o (NS) & o (NS) \\
\hline $10,000-20,000$ & o & o (NS) & o (NS) \\
\hline $20,000-30,000$ & 0 & o (NS) & o (NS) \\
\hline $30,000-40,000$ & 1 & o (NS) & o (NS) \\
\hline 240,000 & 4 & o (NS) & $4(1: 40$ to $1: 320)$ \\
\hline \multicolumn{4}{|l|}{ Bovine $n=7$} \\
\hline \multicolumn{4}{|c|}{ MERS-CoV antigen array signal (RFU) } \\
\hline$\langle 10,000$ & 7 & o (NS) & $7(1: 80$ to $1:>1,280)$ \\
\hline $10,000-20,000$ & o & o (NS) & o (NS) \\
\hline $20,000-30,000$ & 0 & o (NS) & o (NS) \\
\hline $30,000-40,000$ & 0 & o (NS) & o (NS) \\
\hline 240,000 & 0 & o (NS) & o (NS) \\
\hline \multicolumn{4}{|c|}{ hCoV-OC43 antigen array signal (RFU) } \\
\hline$\langle 10,000$ & 4 & o (NS) & $4(1: 80$ to $1: 160)$ \\
\hline $10,000-20,000$ & 3 & o (NS) & $3(1: 160$ tp $1:>1,280)$ \\
\hline $20,000-30,000$ & 0 & o (NS) & o (NS) \\
\hline $30,000-40,000$ & 0 & o (NS) & o (NS) \\
\hline$>40,000$ & 0 & o (NS) & o (NS) \\
\hline
\end{tabular}

BCoV: bovine coronavirus; hCoV-OC43: human coronavirus OC43; MERS-CoV: Middle East Respiratory Syndrome virus; NS: not shown; PRNT: plaque reduction neutralisation test; RFU: relative fluorescence units.

${ }^{a}$ based on both microneutralisation with starting dilution 1:10 and PRNT with starting dilution 1:40.

${ }^{\mathrm{b}}$ based on PRNT with starting dilution 1:40. 
region in Jordan where a cluster of human MERS cases occurred.

No evidence for the presence of antibodies directed against MERS-CoV was found in 91 cattle and 150 goat sera. MERS-CoV neutralising antibodies were found in all 11 dromedary camel sera. Circulation of BCoV in dromedary camels is known but cross-neutralisation between MERS-CoV (a lineage $C$ beta-coronavirus) and $\mathrm{BCoV}$ (a lineage A beta-coronavirus) or other CoVs, including SARS-CoV (a lineage B betacoronavirus), has been conclusively excluded in previous studies and was illustrated again in this study in the comparative PRNTs $[8,9]$. These observations indicate that MERS-CoV or a highly related virus circulated in dromedary camels in a region where transmission to humans occurs.

The neutralisation titres observed in the Jordan camel sera were lower than observed with sera from Oman but in the same range as those observed on the Canary Islands [9]. The dromedary camels in this study were calves, only three to 14 months of age, and these low titres might reflect the presence of waning maternal antibodies. However, maternal antibodies in dromedary camels reportedly decline rapidly two to five weeks after birth [12] and much higher antibody titres against MERS-CoV were observed in adult dromedary camels (older than four years of age) in the MiddleEast region and the Horn of Africa $[8,9]$ (and data not shown). Therefore an alternative explanation could be that the camels had just been infected and antibody titres were still rising.

Interestingly, six sheep sera reacted with MERS-CoV S1 antigen on the array while previous validation experiments using sheep sera from the Netherlands showed no reactivity [9]. This previous study included $\mathrm{HCoV}-\mathrm{OC}_{43}$ S1-reactive and non-reactive sheep sera emphasising that there should not be any cross-reactivity between the MERS-CoV antigen and BCoV-specific antibodies due to BCoV circulation. However, none of the 126 sheep sera showed MERS-CoV neutralising activity. The applied sheep sera were highly haemolytic which may have caused some assay interferences.

Our observation strengthens our earlier study in which MERS-CoV neutralising antibodies were found in dromedary camels in Oman where human cases have been reported as well [2]. Until the virus that elicits these antibodies in camels is detected, sequenced and compared to the viruses sequenced from human patients, it remains unclear whether this livestock species is indeed infected with MERS-CoV and thus represents an immediate source for human infection. However, our observations should be used to focus virological and serological studies in livestock, especially dromedary camels and sheep, and including humans handling these animals and their products.
Acknowledgements

Janko van Beek is acknowledged for assistance with figure 2. $B H, C D$ and $A O$ were funded by the European Union $F P 7$ project EMPERIE (contract number 223498). AO, CD and MK were funded by ANTIGONE (contract number 278976).

\section{Conflict of interest}

None declared.

\section{Authors' contributions}

CR: coordinated the study, assisted in designing the study, analysed data, wrote manuscript. MA: sample collection, assisted in designing the study, drawing figure 1 , read and revised manuscript. VSR: performed laboratory testing, analysed data, read and revised manuscript. BM: performed laboratory testing, analysed data, read and revised manuscript. AE: sample collection, read and revised manuscript. SA: sample collection, read and revised manuscript. GJG: performed laboratory testing, analysed data, read and revised manuscript. TMB: performed laboratory testing, analysed data, read and revised manuscript. IZ: performed laboratory testing, read and revised manuscript. MAM: data analysis, read and revised manuscript. BJB: produced design antigen, provided antigens, read and revised the manuscript. PJR: read and revised the manuscript. AO: read and revised the manuscript. $C D$ : read and revised the manuscript. $\mathrm{BH}$ : assisted in designing the study, analysed data, read and revised manuscript. MK: assisted in designing the study, analysed data, read and revised the manuscript.

\section{References}

1. Hijawi B, Abdallat M, Sayaydeh A, Alqasrawi S, Haddadin $A$, Jaarour N, et al. Novel coronavirus infections in Jordan, April 2012: epidemiological findings from a retrospective investigation. East Mediterr Health J. 2013;19 Suppl 1:S12-8. PMid:23888790

2. World Health Organization (WHO). Global Alert and Response (GAR): Middle East respiratory syndrome coronavirus (MERS(oV) - update 29 November 2013. Geneva: WHO. [Accessed 29 Nov 2013]. Available from: http://www.who.int/csr/ don/2013_11_29/en/index.html

3. Penttinen PM, Kaasik-Aaslav K, Friaux A, Donachie A, Sudre B, Amato-Gauci AJ, et al. Taking stock of the first 133 MERS coronavirus cases globally - Is the epidemic changing? Euro Surveill. 2013;18(39):pii=20596. Available from: http://www. eurosurveillance.org/ViewArticle.aspx?Articleld=20596 PMid:24094061

4. FAOSTAT 2013. Rome: Food and Agriculture Organization of the United Nations. [Accessed: 17 Jun 2013]. Available from: http:// faostat3.fao.org/home/index.html

5. Drosten C, Seilmaier M, Corman VM, Hartmann W, Scheible G, Sack S, et al. Clinical features and virological analysis of a case of Middle East respiratory syndrome coronavirus infection. Lancet Infect Dis. 2013;13(9):745-51. http://dx.doi.org/10.1016/S1473-3099(13)70154-3

6. Cotten M, Watson SJ, Kellam P, Al-Rabeeah AA, Makhdoom HQ, Assiri A, et al. Transmission and evolution of the Middle East respiratory syndrome coronavirus in Saudi Arabia: a descriptive genomic study. Lancet. 2013. Sep 19.

7. Cotten M, Lam TT, Watson SJ, Palser AL, Petrova V, Grant $P$, et al. Full-genome deep sequencing and phylogenetic analysis of novel human betacoronavirus. Emerg Infect Dis. 2013;19(5):736-42B.

http://dx.doi.org/10.3201/eid1905.130057 PMid:23693015 PMCid:PMC3647518

8. Perera RA, Wang P, Gomaa MR, El-Shesheny R, Kandeil A, Bagato 0 , et al. Seroepidemiology for MERS coronavirus using microneutralisation and pseudoparticle virus neutralisation assays reveal a high prevalence of antibody in dromedary camels in Egypt, June 2013. Euro Surveill. 2013;18(36): $\mathrm{pii}=20574$. Available from: http://www.eurosurveillance.org/ ViewArticle.aspx?Articleld $=20574$ PMid:24079378 
9. Reusken CB, Haagmans BL, Müller MA, Gutierrez C, Godeke GJ, Meyer B, et al. Middle East respiratory syndrome

coronavirus neutralising serum antibodies in dromedary camels: a comparative serological study. Lancet Infect Dis. 2013;13(10):859-66

http://dx.doi.org/10.1016/S1473-3099(13)70164-6

10. Anonymous. Hajj. [Accessed 25 Nov 2013]. Available from: http://en.wikipedia.org/wiki/Hajj

11. Reusken C, Mou H, Godeke GJ, van der Hoek L, Meyer B, Müller MA, et al. Specific serology for emerging human coronaviruses by protein microarray. Euro Surveill. 2013;18(14):pii=20441. Available from: http://www.eurosurveillance.org/ViewArticle. aspx?Articleld $=20441$

PMid:23594517

12. Wernery U. Camelid immunoglobulins and their importance for the new-born--a review. J Vet Med B Infect Dis Vet Public Health. 2001;48(8):561-8

http://dx.doi.org/10.1046/j.1439-0450.2001.00478.x

PMid:11708675 